\title{
Incidence of Asiatic Citrus Canker on Trifoliate Orange and Its Hybrid Accessions in a Florida Field Planting
}

\author{
Ed Stover \\ U.S. Horticultural Research Laboratory, U.S. Department of Agriculture, \\ Agricultural Research Service, 2001 S. Rock Road, Fort Pierce, FL 34945
}

Chandrika Ramadugu and Mikeal Roose

University of California Riverside, 900 University Avenue, Riverside, CA 92521

\section{Joseph Krystel}

U.S. Horticultural Research Laboratory, U.S. Department of Agriculture, Agricultural Research Service, 2001 S. Rock Road, Fort Pierce, FL 34945

Richard F. Lee and Manjunath Keremane

National Clonal Germplasm Repository for Citrus and Dates, U.S. Department of Agriculture, Agricultural Research Service, 1060 Martin Luther King Blvd., Riverside, CA 92507

Additional index words. Xanthomonas citri pv. citri, resistance, Aurantioideae, Rutaceae

Abstract. Asiatic citrus canker (ACC) foliar lesions were evaluated on progenies of 84 seed-source genotypes ("parent genotypes") from the Citrus Variety Collection (CVC) of the University of California at Riverside (UCR) of Citrus trifoliata and hybrids between $C$. trifoliata and other Citrus species and hybrids. Trees were planted Aug. 2013 in a completely randomized design at the Fort Pierce U.S. Department of Agriculture (USDA) grove. Plants were assessed visually Aug. 2017, Sept. 2019, and Sept. 2020 for distinctive ACC lesion incidence and severity. Progeny were compared by parent genotypes using nonparametric analysis. Incidence of ACC [percentage of leaves displaying symptoms, verified by quantitative polymerase chain reaction (qPCR) to be associated with Xanthomonas citri pv. citri] across parent genotypes ranged from $8 \%$ to $80 \%$ (mean, $49 \%$ ) of leaves affected in 2017 , from $4 \%$ to $58 \%$ (mean, $29 \%$ ) in 2019 , and $8 \%$ to $46 \%$ (mean, $25 \%$ ) in 2020 . In 2017 , of 49 C. trifoliata parent genotypes, only four separated from the two highest ACC-incidence statistical categories [Citrus Research Center (CRC) 3345, 3484, 3888, and 4017]. whereas 29 of the 35 C. trifoliata hybrids displayed lower ACC incidence, which separated from the two highest statistical categories. In 2019, of the $C$. trifoliata, only six separated from the highest ACC-incidence statistical category (CRC 3330, 3484, 3547, 3549, 3876, and 3888), whereas all 35 C. trifoliata hybrids displayed lower ACC incidence and separated from the highest statistical category, and 26 hybrids separated from 18 of the $C$. trifoliata. In 2020, only three $C$. trifoliata separated from the highest ACC-incidence statistical category (CRC 2861, 3549, and 3888) and 20 hybrids separated from 18 of the $C$. trifoliata. By parent genotype, ACC incidence correlated substantially between each pair of the 3 years, with $\boldsymbol{r}^{2}$ values of $0.39,0.57$, and 0.65 . Of 34 hybrids validated, similar numbers had $C$. trifoliata, grapefruit $(C$. $\times$ aurantium var. racemosa), and sweet orange $(C$. $\times$ aurantium var. sinensis) chloroplasts. Chloroplast type affected ACC incidence and severity, but not in a consistent manner. Near-isogenic groups within $C$. trifoliata, as determined by DNA markers, were associated with some statistically different ACC sensitivity. Overall, hybrids of $C$. trifoliata with other citrus types displayed markedly reduced ACC sensitivity compared with $C$. trifoliata, indicating that this trait is readily overcome through breeding.

Asiatic citrus canker (ACC, caused by Xanthomonas citri pv. citri, $\mathrm{Xcc}$ ) is now widespread in Florida citrus (Gottwald et al., 2002; Irey et al., 2006). In the field, ACC is spread primarily by wind-driven rain, but can also be transferred by equipment and personnel, and affects foliage and fruit (Gottwald et al., 2002).

Highly susceptible plants often develop severe symptoms on leaves, twigs, and fruit, resulting in premature fruit and leaf drop, and marked scarring on harvested fruit. The use of resistant cultivars is desirable to limit damage from ACC and to reduce costs for control.

This study was established to assess the relative huanglongbing (HLB) sensitivity of Citrus trifoliata (trifoliate orange, previously Poncirus trifoliata) accessions and a diverse assortment of its hybrids, as some members of this species have been shown to be HLB tolerant in an earlier study (Ramadugu et al., 2016), and to confer HLB tolerance to many of its hybrids (e.g., Stover et al., 2015). Although showing low sensitivity to HLB, some trifoliate orange hybrids have been reported to be very sensitive to ACC (e.g., Stover et al., 2013), potentially a negative trait transferred when breeding for HLB tolerance. Therefore, in our study, we assessed the severity of foliar ACC lesions on progeny from 84 parent genotypes of $C$. trifoliata and its hybrids exposed to naturally occurring Xcc inoculum in the field in East-Central Florida to identify their relative susceptibility to ACC.

\section{Materials and Methods}

Source, identity, and naming of plant material. Seeds for all progenies were provided by the USDA-Agricultural Research Service (ARS) National Clonal Germplasm Repository for Citrus and Dates at UCR, and were harvested from fruit of field-grown trees in the CVC of UCR (see http://www.citrusvariety. ucr.edu). Accessions in the CVC are designated with $\mathrm{CRC}$ numbers. The seedling progenies of 84 seed-source accessions were used in this study and are referred to by the CRC number of the seed parent accession. The online version of Table 1 provides access through hyperlinks to the history of each accession with taxonomic references, from the CVC (CRC) and the Germplasm Resource Information Network-Global of the USDA-ARS National Plant Germplasm System. Within the genus Citrus, incidence of nucellar embryony varies greatly [reviewed in Frost and Soost (1968)]; therefore, some of the plants we tested were essentially identical genetically to the female parent (seeds serving as clonal propagules), whereas others were half-sib hybrids of known seed parents but with undetermined pollen parents. As described later, the vast majority of these trees are expected to result from nucellar embryony. For convenience, they are referred to as "accessions," using the CRC numbers of the seed source accessions. Hereafter, the seed source accessions providing the progeny used in this study are referred to as "parent genotypes."

Plant development and maintenance. Seedling development, field planting, and general care were conducted as described in Richardson et al. (2011) and Westbrook et al. (2011), and were typical for citrus production, except with minimal pesticide application. Before field planting, seedlings were maintained in a greenhouse free of asian citrus psyllid [vector of Candidatus Liberibacter asiaticus (CLas), causal agent of HGB] and other arthropod pests. Plants were sown for germination in Jan. 2012, with some resown in June 2012 where germination was initially low. As a component of the 
HLB-related investigation, half of the seedlings from each parent genotype were bud-inoculated with CLas in the greenhouse in Oct. 2012, and all were field-planted during Aug. 2013. In our study, plants were evaluated for ACC 5 to 8 years after germination.

Trees were typically sprayed every 2 weeks with 435 horticultural oil and 200 ppm MagnaBon (Magna-Bon II LLC, Okeechobee, FL). In a few instances, spraying was suspended for 2 months or more for insect observations in other studies. The nutritional component varied throughout the year and included a wide range of products. The list of materials included 20N-4.4P-16.6K, 14N-0.9P-11.6K, Keyplex 1400 DP (Keyplex, Winter Park, FL), Ocean Organics seaweed extract (Ocean Organics, Ann Arbor, MI), and N-Sure 28N-0P-0K (Tessenderlo Kerley, Inc., Phoenix, AZ). Other nutrients were included periodically, but none that were considered to have any effects on canker.

Assessing ACC sensitivity. Formation of foliar lesions indicative of ACC is affected by stage of leaf development when exposed to Xcc (Gottwald and Graham, 1992; Graham and Gottwald, 1991; Vernière et al., 2003). Wind-driven rain is the main factor in field spreading of inoculum (Graham et al., 1992), and the combination of conducive environmental conditions and available inoculum must coincide with foliage susceptibility for ACC development. For these reasons, we assessed ACC presence as both incidence (percentage of leaves displaying lesions) and severity (the percentage of leaf area affected by lesions). ACC symptoms were assessed in Aug. 2017, Sept. 2019, and Sept. 2020. The visual estimates of leaf area disease (ACC severity) were guided by a standard area diagram set prepared using image analysis as described in another study (Bock et al., 2010). In 2017, the overall percentage of leaf area displaying ACC lesions on each tree was assessed but was found to display little mean

Received for publication 4 Jan. 2021. Accepted for publication 9 Feb. 2021.

Published online 3 May 2021.

We thank Ellen Cochrane for greenhouse care; Sean Reif, Jefferson Shaw, and Diego Garcia for data collection in the field; Stephen Mayo for overseeing tree general maintenance; and Spencer Marshall for quantitative polymerase chain reaction (qPCR) diagnostics. Dr. Dean Gabriel kindly provided a culture of $X$. euvesicatoria $\mathrm{pv}$. citrumelonis for use as a qPCR positive control.

This research was originally presented at the 2020 annual meeting of the Florida State Horticultural Society.

This article reports the results of research only. Mention of a trademark or proprietary product is solely for the purpose of providing specific information and does not constitute a guarantee or warranty of the product by the U.S. Department of Agriculture and does not imply its approval to the exclusion of other products that may also be suitable.

R.F.L. is retired.

E.S. is the corresponding author. E-mail: ed.stover@usda.gov.

This is an open access article distributed under the CC BY-NC-ND license (https://creativecommons. org/licenses/by-nc-nd/4.0/). separation; so, in 2019 and 2020, the percentage of leaf area displaying ACC lesions only on the most severely affected leaf was assessed on each tree.

Statistical analyses. We tested whether the incidence and severity of ACC differed among progenies of the 86 parent genotypes using Kruskal Wallis nonparametric analysis (PROC GLIMMIX, SAS 9.4; SAS Institute Inc., Cary, NC). Regressions were conducted using Microsoft Excel (Microsoft Office version 2016; Microsoft Corporation, Redmond, WA).

qPCR verification of pathogen associated with symptoms. Verification that purported ACC lesions were in fact a result of infection with Xcc was conducted by qPCR analysis. Four trees were selected randomly for sampling of well-known accessions from each of pure $C$. trifoliata, citranges, citrumelos, US-119 (the only unifoliate hybrid in the trial), and four unifoliates from adjoining rows. Four leaves showing clear canker lesion symptoms were sampled from different branches on each tree. Lesions and the surrounding area, $\approx 200 \mathrm{mg}$ of tissue, were excised and macerated for DNA extraction. Carrizo and Hamlin leaves from clean greenhouse trees, extracted in the same manner, were used as negative controls.

DNA was isolated using the ZR-Duet Quick-DNA/RNA Miniprep Plus Kit (Zymo Research, Irvine, CA) according to the manufacturer's instructions. DNA concentration and purity were analyzed using a NanoDrop 8000 spectrophotometer (Thermo Fisher Scientific, Waltham, MA). qPCR was performed using the PowerUp SYBR Green master mix (Thermo Fisher Scientific) and $100 \mathrm{ng}$ of template on the Applied Biosystems AB7500 Real-Time qPCR system (Thermo Fisher Scientific) according to the manufacturer's instructions. Primer sets (Cubero and Graham, 2002) were specific to the 16 s ribosomal DNA sequence of $X$. euvesicatoria pv. citrumelonis [abbreviated hereafter as Xec; recent synonyms $X$. alfalfae pv. citrumelonis (Constantin et al., 2016), $X$. axonopodis ssp. citrumelonis, and $X$. campestris pv. citrumelo (National Center for Biotechnology Information, 2020)], lrp gene conserved in Xanthomonas spp., pth gene conserved in Xcc strains, and citrus Glyceraldehyde 3-phosphate dehydrogenase as a reference gene. DNA was isolated from liquid cultures of Xcc (strain ID 3213 from D. Gabriel) and Xec (strain ID 3048 from D. Gabriel) using phenol, phenol-chloroform-isoamyl alcohol $(25: 24: 1)$, followed by two $70 \%$ ethanol washes. The dried pellet was then resuspended in $100 \mu \mathrm{L} 10 \mathrm{~mm}$ Tris buffer ( $\mathrm{pH}$ 8.5) for use as positive controls. In addition to the clean citrus DNA controls described, standard water controls were also included.

Single nucleotide polymorphism analysis of chloroplasts. To determine chloroplast identities, comparisons were made using data on 462 well-distributed chloroplast single nucleotide polymorphisms (SNPs) included on a 50,000 + SNP chip developed at UCR with polymorphic SNPs selected based on sequences of 41 diverse accessions from the UCR CVC and public databases (Hiraoka, 2020).

\section{Results and Discussion}

ACC pathogen widespread in trial. ACC was ubiquitous in the research farm where this experiment was conducted. The lesions caused by Xcc infection initially have a distinct yellow halo, which often becomes necrotic, and the lesions feel sandpapery on the abaxial and adaxial surfaces of the leaves, and raised lesions form on the stems as well (Das, 2003). These traits were displayed in all trees throughout the planting. Virtually all lesions had progressed beyond the yellow halo stage in the trial planting, even though neighboring unifoliate citrus-citrus with a leaf composed of a single leaflet rather than the compound trifoliate (3-leaflet) leaf of $C$. trifoliata and its F1 hybrids-maintained many halos. The bacterium Xec, causal agent of Citrus bacterial spot, is also present in Florida and produces similar symptoms, but is generally reportedly prevalent only in nurseries and is associated with frequent mechanical injury (budding and pruning) to trees [reviewed in Graham and Gottwald (1991]. More recently, there are unpublished reports that the HLB-tolerant cultivar LB8-9 (SugarBelle(C) is highly susceptible to Xec but not $\mathrm{Xcc}$, but lesions are only found on leaves and never fruit (F.G. Gmitter, Jr., personal communication). For our study, qPCR with primers to distinguish the two Xanthomonas species (data not shown) was run on ACCsymptomatic leaves from the test plot and adjoining rows, and all tested strongly positive for Xcc [all but two with a cycle threshold (Ct) $<25$, one at $\mathrm{Ct} 30.9$ and one at $\mathrm{Ct} 26.0$ (mean, 22.6), reflecting a mean copy number of 240,000 per ng plant DNA]; only $44 \%$ had detectable Xec and then at very low titers (Ct, >35.4; a mean copy number of 4 per $n g$ DNA). Therefore, the distinctive canker lesions were attributed to Xcc.

ACC sensitivity in accessions. CLas inoculation before planting had no effect on ACC, thus all plants of an accession were assessed as a single group (data not shown). Almost all accessions with a lower ACC lesion incidence were $C$. trifoliata hybrids rather than pure $C$. trifoliata in all 3 years of data collection (Table 1). To aid in visualizing the responses across all accessions, pure $C$. trifoliata accessions are in bold in the leftmost column of Table 1; in each year for incidence and severity of ACC, the accession means that separated statistically are shaded in gray for low incidence and in bold for high incidence.

Incidence of ACC across parent genotypes ranged from $8 \%$ to $80 \%$ (mean, $49 \%$ ) of leaves affected in 2017, from $4 \%$ to $58 \%$ (mean, 29\%) in 2019, and $8 \%$ to $46 \%$ (mean, $25 \%$ ) in 2020 . In 2017 , of 49 C. trifoliata parent genotypes, only four separated from the two highest ACC-incidence statistical categories (CRC 3345, 3484, 3888, and 4017), whereas 29 of the 35 C. trifoliata hybrids displayed lower ACC incidence, which separated from the two highest statistical categories (the two highest were used for this comparison because so few accessions were in the highest group). In 2019, of the C. trifoliata, 


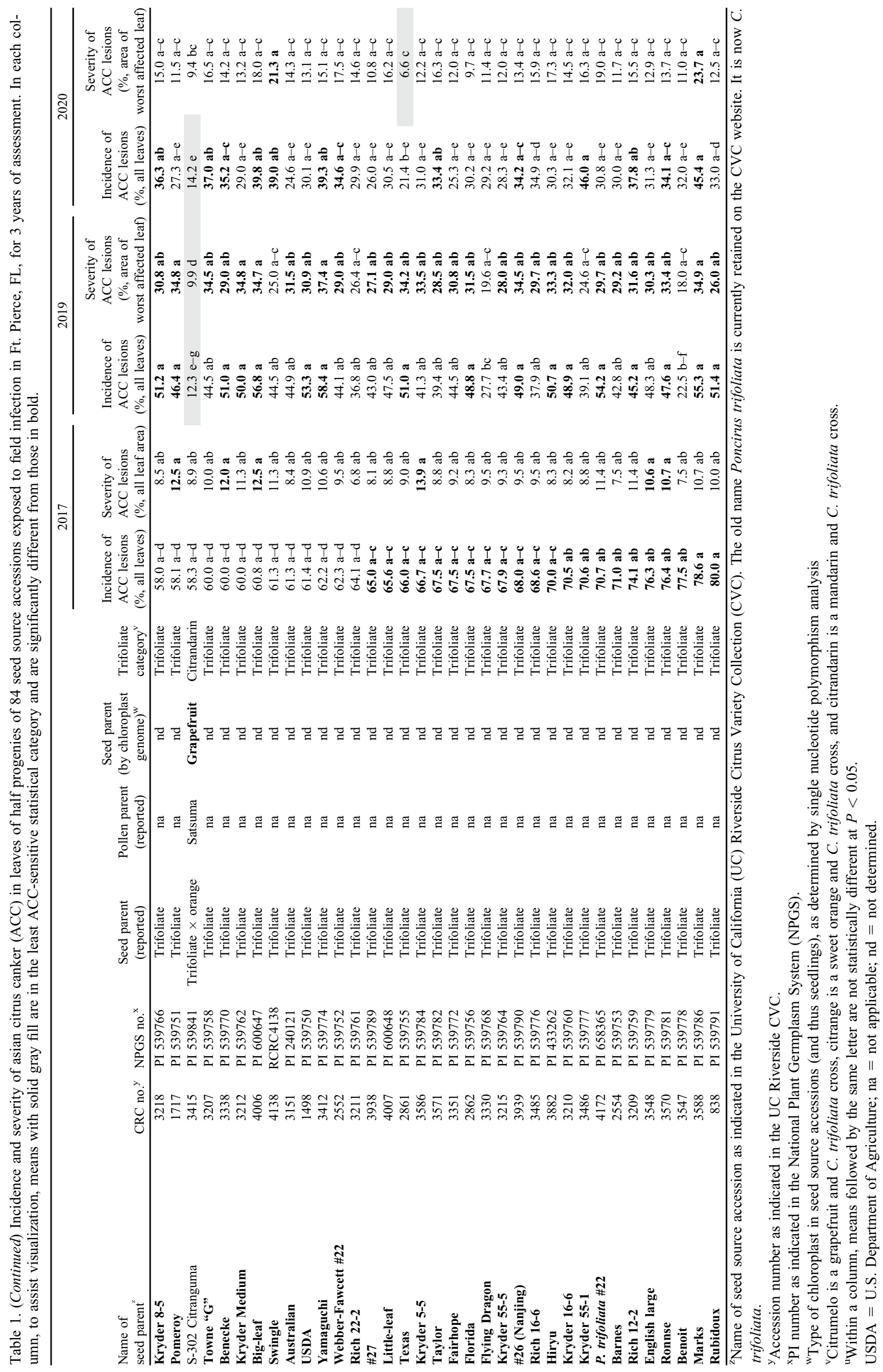


only six separated from the highest ACC-incidence statistical category (CRC 3330, 3484, $3547,3549,3876$, and 3888), whereas all 35 C. trifoliata hybrids displayed lower ACC incidence and separated from the highest statistical category, and 26 hybrids separated from 18 of the $C$. trifoliata. In 2020, only five $C$. trifoliata separated from the highest ACC-incidence statistical category (CRC 2861, 3484, 3549,3888 , and 4008) and 20 hybrids separated from 18 of the C. trifoliata. C. trifoliata accessions CRC 3484, 3549, and 3888 are noteworthy for their separation from the highest ACC-incidence category in 2 or 3 years. Only CRC 3888 had this distinction in all 3 years, but it should be noted that there was only one tree surviving and, because its parent accession is reported to be monoembryonic, it is likely a self-pollinated seedling or a hybrid. It was among the lowest accessions in canker sensitivity by all metrics in all 3 years and merits further investigation. We will propagate this one tree and test for ACC sensitivity in a replicated trial against appropriate standards. It is reported that in openpollinated seedlings of $C$. trifoliata accessions at the UCR CVC, all zygotic seedlings were selfs or crosses between $C$. trifoliata accessions, likely a result of earlier flowering compared with other citrus (Kepiro and Roose, 2009). If this is a self or a hybrid with another trifoliate, it could prove useful in understanding more fully the genetics of ACC sensitivity.

By accession means, ACC incidence correlated between each pair of the 3 years, with $r^{2}$ values of $0.39,0.57$, and 0.65 (Table 2). Within each year, metrics of ACC severity correlated with incidence of ACC, with $r^{2}$ values of $0.26,0.94$, and 0.42 for 2017, 2019, and 2020 , respectively.

ACC sensitivity within citrumelos and citranges. Citrumelo, the name given to hybrids of grapefruit and trifoliate orange, is widely used as citrus rootstock, and 'Swingle' citrumelo has been the most widely used citrus rootstock in Florida for the past 30 years (Florida Department of Agriculture and Consumer Services, 2016, 2020). Three of the 10 citrumelo accessions in our trial are independent entries of 'Swingle' (CRC 3341, 3771, and 3767), which were verified by SNP analysis, and all were consistently among the least ACC-sensitive accessions (Table 1). Most citrumelo accessions did not separate from the least ACC-sensitive category across all 3 years ( 9 in 2017, 8 in 2019, and all 10 in
2020). Two citrumelos were among the most ACC-sensitive accessions in this trial in some but not all years (CRC 3348 in 2017, and CRC 3821 in 2019 only), showing significant mean separations for ACC incidence. All citrumelos in the trials had a grapefruit seed parent.

Citrange, the name given to hybrids of sweet orange and trifoliate orange, is also widely used as citrus rootstock, and 'Carrizo'/ 'Troyer' (shown to be the same genotype) is the most widely used citrus rootstock in California and second-most widely used in Florida for the past 30 years (Florida Department of Agriculture and Consumer Services, 2016, 2020). Of the 14 citrange accessions, 'Morton' and 'Rusk' were duplicated, and 'Carrizo' matched 'Troyer' by SNP analysis (Roose unpublished). By chloroplast analysis, 10 accessions had a sweet orange seed parent and four trifoliate orange. In no year and by no metric were any citranges statistically different from each other in ACC sensitivity (Table 1). Only in 2017 did any citrange fail to fall in the least ACC-sensitive statistical grouping (CRC 271 and 275).

ACC sensitivity by C. trifoliata subgroup. There are four near-isogenic groupings of $C$. trifoliata accessions, designated as restriction fragment length polymorphism (RFLP) types 1 through 4 by Fang et al. (1997), based on an array of molecular methods, and more recently verified by high-density SNP analysis (Roose, unpublished). Among the less ACCsensitive C. trifoliata accessions, CRC 3888 (lowest sensitivity in all 3 years) and CRC 4017 are the only two accessions in this study from the uncommon RFLP type 2, whereas CRC 3484 and CRC 3549 are in the major group RFLP type 3, corresponding to the established "small flower trifoliate" group. For the other common $C$. trifoliata designated as RFLP type 4 (corresponding to large flower trifoliates), only CRC 3345 displayed ACC incidence that separated from the two most severe statistical groupings, and only in 2017. CRC 3938 was the only RFLP type 1 accession, and it was in the highest ACC sensitivity group in all 3 years for all metrics. Statistical analysis of all C. trifoliata accessions by RFLP types showed type 2 to be significantly less sensitive than other types for ACC incidence only in 2017 (Table 3). A separate analysis comparing types 3 and 4 only (because they were much more numerous) showed type 3 accessions to be less

Table 2. $r^{2}$ Values from regressions of incidence and severity of asian citrus canker (ACC) in leaves of half progenies of 84 seed source accessions exposed to field infection in Ft. Pierce, FL, for 3 years (2017, 2019, and 2020) of assessment. Statistical significance of all regressions exceeds $P<10^{-7}$.

\begin{tabular}{lccccc}
\hline Incidence of canker & SOC $^{\mathrm{z}}, 2017$ & IOC $^{\mathrm{y}}, 2019$ & SOC, 2019 & IOC, 2020 & SOC, 2020 \\
\hline 2017 & 0.26 & 0.57 & & 0.39 & \\
2019 & & & 0.94 & 0.65 & 0.42 \\
2020 & & & & &
\end{tabular}

${ }^{\mathrm{z}} \mathrm{SOC}$ is severity of canker lesions in the indicated year, measured as a percentage of the total canopy per tree covered by ACC lesions in 2017 and the percentage of the most symptomatic leaf per tree in 2019 and 2020.

${ }^{\mathrm{y}} \mathrm{IOC}$ is incidence of canker lesions in the indicated year, measured as a percentage of all leaves on a tree showing ACC lesions. sensitive by metrics of ACC severity in all 3 years and by ACC incidence only in 2019 .

ACC severity showed less robust mean separation in all 3 years (Table 1) and seemingly provided no noteworthy additional inferences. Because only a few accessions displayed statistically different means in 2017, these data are excluded from Table 1, but are presented here: Citrumelo CRC 1452 and trifoliates CRC 1717, 3338, 3548, 3570, 3586,4006 , and 4008 had a significantly greater percentage of canopy covered by lesions $(10.6 \%$ to $13.9 \%)$ than trifoliate CRC $3587(5.0 \%)$.

ACC sensitivity as affected by chloroplast type. The UCR database on SNPs permitted assessment of the actual seed parent of the hybrids, as the cytoplasm is largely derived from the maternal parent in citrus (Abkenar et al., 2004). Eleven of the hybrids were the reciprocal cross from that expected, with the "female first" listing rule not observed. These are indicated by bold text in the "Seed parent (by chloroplast genome)" column (Table 1). 'Yuma' was previously found to be a citrumelo rather than a citrange (Xiang and Roose, 1988), and has a grapefruit chloroplast. Of the 34 hybrids with chloroplasts validated, similar numbers of field seedlings had trifoliate, grapefruit, and sweet orange chloroplasts $(74,91$, and 91 , respectively), permitting the assessment of chloroplast influence on ACC sensitivity. The analyses were conducted in two ways: 1) by evaluating trifoliate vs. grapefruit vs. sweet orange chloroplasts separately or 2) by combining sweet orange and grapefruit chloroplasts into a "pummelo" chloroplast category, because both sweet orange and grapefruit chloroplasts are known to be of pummelo origin (Nicolosi et al., 2000), although they are somewhat different from each other (Carbonell-Caballero et al., 2015). In all years, chloroplast type significantly but modestly affected ACC incidence and/or severity, but not in a consistent manner (Table 4). This analysis was conducted because Omar et al (2017) reported that replacing the grapefruit chloroplast with that of 'Meiwa' kumquat reduced ACC sensitivity markedly. 'Meiwa' is markedly ACC insensitive, but sweet orange is only somewhat less ACC sensitive compared with grapefruit and trifoliate orange.

ACC sensitivity comparison with previous studies. In an earlier study of more diverse citrus accessions, we reported incidence of ACC in Sept. 2010 and 2012 (Stover et al., 2013). That study included two shared C. trifoliata accessions (CRC 4007 and 3549) and three shared C. trifoliata hybrid accessions (CRC 301, 3771, 3957), but results were rather different. The only statistically significant difference among these accessions in 2010 and 2012 was that CRC 3771 ('Swingle' citrumelo) had a significantly greater reported ACC incidence (Sept. $2010,62 \%$ of leaves vs. $34 \%$ to $37 \%$; Sept. 2012 , $28 \%$ vs. $6 \%$ to $11 \%$ ) than the other accessions, and indeed was among the highest in the entire trial. In contrast, in 2017 and 2019, CRC 3771 was significantly lower in canker incidence compared with one or both 
Table 3. Association with restriction fragment length polymorphism (RFLP) type for incidence and severity of asian citrus canker (ACC) in leaves of progenies of 49 seed source C. trifoliata accessions exposed to field infection in Ft. Pierce, FL, for 3 years $(2017$, 2019, and 2020) of assessment.

\begin{tabular}{|c|c|c|c|c|c|c|c|}
\hline \multirow[b]{2}{*}{ RFLP type ${ }^{z}$} & \multirow[b]{2}{*}{$\mathrm{N}, 2020$} & \multicolumn{2}{|c|}{2017} & \multicolumn{2}{|r|}{2019} & \multicolumn{2}{|r|}{2020} \\
\hline & & $\begin{array}{l}\text { Incidence of } \\
\text { ACC lesions } \\
(\% \text {, all leaves) }\end{array}$ & $\begin{array}{c}\text { Severity of } \\
\text { ACC lesions } \\
(\% \text {, all leaf area) }\end{array}$ & $\begin{array}{l}\text { Incidence of } \\
\text { ACC lesions } \\
(\%, \text { all leaves })\end{array}$ & $\begin{array}{c}\text { Severity of } \\
\text { ACC lesions } \\
(\% \text {, worst affected leaf area) }\end{array}$ & $\begin{array}{l}\text { Incidence of } \\
\text { ACC lesions } \\
(\%, \text { all leaves })\end{array}$ & $\begin{array}{c}\text { Severity of } \\
\text { ACC lesions } \\
(\% \text {, worst affected leaf area) }\end{array}$ \\
\hline 2 & 3 & $25.0 \mathrm{~b}$ & $6.0 \mathrm{~b}$ & $38.0 \mathrm{a}$ & $34.5 \mathrm{a}$ & $25.7 \mathrm{a}$ & $9.5 \mathrm{a}$ \\
\hline 3 & 153 & $62.5 \mathrm{a}\left(\mathrm{A}^{\mathrm{x}}\right)$ & $8.7 \mathrm{ab}(\mathrm{B})$ & $41.1 \mathrm{a}(\mathrm{B})$ & $27.8 \mathrm{a}(\mathrm{B})$ & $30.4 \mathrm{a}(\mathrm{A})$ & $13.3 \mathrm{a}(\mathrm{B})$ \\
\hline 4 & 171 & $61.6 \mathrm{a}(\mathrm{A})$ & $10.5 \mathrm{a}(\mathrm{A})$ & $47.1 \mathrm{a}(\mathrm{A})$ & $31.2 \mathrm{a}(\mathrm{A})$ & $34.1 \mathrm{a}(\mathrm{A})$ & $15.0 \mathrm{a}(\mathrm{A})$ \\
\hline
\end{tabular}

${ }^{\mathrm{z}}$ RFLP type reflects near-isogenics groups within the tested C. trifoliata accessions, as designated by Fang et al. (1997).

${ }^{\mathrm{y}}$ Within a column, means followed by the same lowercase letter are not statistically different at $P<0.05$.

${ }^{\mathrm{x}}$ Within a column, means followed by the same uppercase letter are not statistically different at $P<0.05$, from a separate analysis restricted to type 3 and type 4 accessions.

Table 4. Association with chloroplast type for incidence and severity of asian citrus canker (ACC) in leaves of half-sib progenies of 84 seed source accessions exposed to field infection in Ft. Pierce, FL, for 3 years $(2017,2019$, and 2020) of assessment.

\begin{tabular}{|c|c|c|c|c|c|c|c|}
\hline \multirow[b]{2}{*}{ Chloroplast } & \multirow[b]{2}{*}{$\mathrm{N}, 2020$} & \multicolumn{2}{|c|}{2017} & \multicolumn{2}{|r|}{2019} & \multicolumn{2}{|r|}{2020} \\
\hline & & $\begin{array}{l}\text { Incidence of } \\
\text { ACC lesions } \\
(\%, \text { all leaves })\end{array}$ & $\begin{array}{c}\text { Severity of } \\
\text { ACC lesions } \\
(\% \text {, all leaf area })\end{array}$ & $\begin{array}{l}\text { Incidence of } \\
\text { ACC lesions } \\
\text { (\%, all leaves) }\end{array}$ & $\begin{array}{c}\text { Severity of } \\
\text { ACC lesions } \\
(\% \text {, worst affected leaf area })\end{array}$ & $\begin{array}{l}\text { Incidence of } \\
\text { ACC lesions } \\
\text { (\%, all leaves) }\end{array}$ & $\begin{array}{c}\text { Severity of } \\
\text { ACC lesions } \\
(\%, \text { worst affected leaf area })\end{array}$ \\
\hline Trifoliate & 74 & $34.3 \mathrm{a}$ & $6.8 \mathrm{~b}$ & $11.8 \mathrm{a}$ & $10.5 \mathrm{a}$ & $16.7 \mathrm{a}$ & $12.3 \mathrm{a}$ \\
\hline Grapefruit & 91 & $34.2 \mathrm{a}$ & $8.8 \mathrm{a}$ & $15.0 \mathrm{a}$ & $12.1 \mathrm{a}$ & $16.2 \mathrm{~b}$ & $10.6 \mathrm{a}$ \\
\hline Sweet orange & 91 & $36.2 \mathrm{a}$ & $7.3 \mathrm{~b}$ & $11.1 \mathrm{~b}$ & $10.6 \mathrm{~b}$ & $18.3 \mathrm{a}$ & $12.1 \mathrm{a}$ \\
\hline Trifoliate & 74 & $34.3 \mathrm{a}$ & $6.8 \mathrm{~b}$ & $11.8 \mathrm{ab}$ & $10.5 \mathrm{~b}$ & $16.7 \mathrm{ab}$ & $12.3 \mathrm{a}$ \\
\hline
\end{tabular}

${ }^{\mathrm{z}}$ Within a column in each section (pummelo vs. trifoliate or grapefruit vs. sweet orange vs. trifoliate), means followed by the same letter are not statistically different at $P<0.05$.

of the shared C. trifoliata accessions, and lower in severity compared with both $(2019$ only) of these C. trifoliata accessions. As noted earlier, there are two strains of Xanthomonas reported to be in Florida that infect citrus and produce similar symptoms in C. trifoliata and its hybrids (Graham et al., 1990). Infections by the strain of $X$. campestris pv. citri (now Xcc) were reported to be less severe in C. trifoliata than several other citrus types, including 'Swingle' citrumelo, whereas an aggressive strain of $X$. campestris pv. citrumelo (now Xec) was most aggressive in 'Swingle', followed closely by C. trifoliata, and was much less severe in other citrus genotypes tested. In contrast, one of the Xec strains was significantly more severe in C. trifoliata than in 'Swingle' citrumelo, which in turn showed greater lesion diameter than six of seven other citrus genotypes, and only Duncan grapefruit was similar to $C$. trifoliata in response. In another Florida field screening of ACC susceptibility, 'Swingle' citrumelo was reported to be the most susceptible of 10 rootstock and 8 scion genotypes, and this was adjacent to highly infected grapefruit (Futch and Graham, 2012). It seems reasonable that the greater susceptibility of $C$. trifoliata compared to its hybrids, in the trials reported here, is a result of strain differences, perhaps influenced by the planting being all $C$. trifoliata and hybrids rather than being predominately unifoliate citrus. Populations of the most aggressive strain of Xec were reported to be sustained after initial inoculation in $C$. trifoliata and hybrids, but not in other citrus types tested, in which the inoculum was undetectable at $40 \mathrm{~d}$ (Graham et al., 1990). Because spread and establishment of the canker pathogen is largely dependent on wind-driven rain and the stage of leaf development when exposed, weather conditions when leaves are susceptible can have a major impact on disease development (i.e., Bock et al., 2014)

Literature support for predominance of nucellar embryony. In unpublished work, 50 seeds of each of $68 C$. trifoliata accessions were evaluated visually for polyembrony (D. Hutchinson, personal communication), and 61 of them displayed greater than $80 \%$ of seeds as polyembryonic. Of these accessions, 24 were also included in our study and all were highly polyembryonic. Similarly, in another study, $14 C$. trifoliata accessions were included in a larger test of citrus accessions, and 12 were predominately polyembryonic (Krueger and Roose, 2003). However, somewhat greater incidences $(\approx 30 \%)$ of zygotic embryo production are reported for some $C$. trifoliata hybrids with sweet orange and grapefruit parents (Xiang and Roose, 1988), and in crosses between 100\% monoembryonic $C$. maxima $\times C$. trifoliata, $92 \%$ of the progeny population produced fewer than $30 \%$ polyembryonic seeds (Kepiro and Roose, 2009).

\section{Caution and Conclusion}

Our study provides data on the relative susceptibility of $C$. trifoliata and its hybrids to ACC. Overall, hybrids of $C$. trifoliata with other citrus types displayed markedly reduced ACC sensitivity compared with $C$. trifoliata, indicating that this trait is readily overcome in breeding. For all 3 years of the study, one accession that was represented by only one tree was much less susceptible to ACC than other accessions of $C$. trifoliata, which merits further investigation. ACC incidence correlated between each pair during the 3 years these trees were evaluated. Chloroplast type affected ACC incidence and severity, but not in a consistent manner. RFLP subgroupings for $C$. trifoliata accessions showed considerable association between RFLP type and ACC sensitivity. In Florida, there are at least three genetically different isolates of Xcc (Cubero and Graham, 2002), and likely many more around the world. Therefore, our results should, cautiously, be considered most relevant within the context of Indian River Xcc isolates. Information on relative susceptibility of diverse accessions of $C$. trifoliata and its hybrids to ACC may prove useful in breeding efforts to reduce ACC susceptibility, and may provide useful guidance for future researchers on mechanisms of resistance and susceptibility.

\section{Literature Cited}

Abkenar, A., S. Isshiki, and Y. Tashiro. 2004. Maternal inheritance of chloroplast DNA in intergeneric sexual hybrids of "true citrus fruit trees" revealed by PCR-RFLP analysis. J. Hort. Sci. Biotechnol. 79:360-363, doi: 10.1080/ 14620316.2004.11511773.

Bock, C.H., J.H. Graham, T.R. Gottwald, A.Z. Cook, and P.E. Parker. 2014. Effect of the duration of inoculum exposure on development of citrus canker symptoms on seedlings of Swingle citrumelo. Eur. J. Plant Pathol. 138:237245, doi: 10.1007/s10658-012-0150-y.

Bock, C.H., G.H. Poole, P.E. Parker, and T.R. Gottwald. 2010. Plant disease severity estimated visually, by digital photography and image analysis, and by hyperspectral imaging. Crit. Rev. Plant Sci. 29:59-107, doi: 10.1080/ 07352681003617285 .

Carbonell-Caballero, J., R. Alonso, V. Ibañez, J. Terol, M. Talon, and J. Dopazo. 2015. A phylogenetic analysis of 34 chloroplast genomes elucidates the relationships between wild and 
domestic species within the genus Citrus. Mol. Biol. Evol. 32:2015-2035.

Constantin, E.C., I. Cleenwerck, M. Maes, S. Baeyen, C. Van Malderghem, P. De Vos, and B. Cottyn. 2016. Genetic characterization of strains named as Xanthomonas axonopodis pv. dieffenbachiae leads to a taxonomic revision of the $X$. axonopodis species complex. Plant Pathol. 65:792-806, doi: 10.1111/ppa.12461.

Cubero, J. and J.H. Graham. 2002. Genetic relationship among worldwide strains of Xanthomonas causing canker in citrus species and design of new primers for their identification by PCR. Appl. Environ. Microbiol. 68:1257-1264, doi: 10.1128/AEM.68.3.1257-1264.2002.

Das, A.K. 2003. Citrus canker: A review. J. Appl. Hort. 5:52-60, doi: 10.37855/jah.2003.v05i01.15.

Fang, D.Q., M.L. Roose, R.R. Krueger, and C.T. Federici. 1997. Fingerprinting trifoliate orange germplasm accessions with isozymes, RFLPs, and inter-simple sequence repeat markers. Theor. Appl. Genet. 95:211-219.

Florida Department of Agriculture and Consumer Services. 2016. Citrus budwood annual report 2015-2016. 18 Nov. 2020. <https://www. fdacs.gov/content/download/72969/file/20152016\%20Annual\%20Report\%20Final.pdf $>$.

Florida Department of Agriculture and Consumer Services. 2020. Citrus budwood annual report 2019-2020. 18 Nov. 2020. <https://www. fdacs.gov/content/download/94009/file/2019-20 20-Annual-Report.pdf $>$.

Futch, S.H. and J.H. Graham. 2012. Susceptibility of common rootstocks and scions to foliar citrus canker under Florida conditions. Proc. Annu. Meet. Fla. State Hort. Soc. 125:47-49.

Frost, H.B. and R.K. Soost. 1968. Seed reproduction: Development of gametes and embryos, p. 290-324. In: W. Reuther, L.D. Batchelor, and H.J. Webber (eds.). The citrus industry. Vol. 2: Anatomy, physiology, genetics, and reproduction. University of California Press, Berkeley, CA.

Gottwald, T.R. and J.H. Graham. 1992. A device for precise and nondisruptive stomatal inoculation of leaf tissue with bacterial pathogens.
Phytopathology 82:930-935, doi: 10.1094/phyto-82-930.

Gottwald, T.R., J.H. Graham, and T.S. Schubert. 2002. Citrus canker: The pathogen and its impact. Plant Health Prog. 3:15-49, doi: 10.1094/ PHP-2002-0812-01-RV.

Graham, J.H. and T.R. Gottwald. 1991. Research perspectives on eradication of citrus bacterial diseases in Florida. Plant Dis. 75:1193-1200.

Graham, J.H., T.R. Gottwald, and D. Fardelmann. 1990. Cultivar-specific interactions for strains of Xanthomonas campestris from Florida that cause citrus canker and citrus bacterial spot. Plant Dis. 74:753-756, doi: 10.1094/PD-74-0753.

Graham, J.H., T.R. Gottwald, T.D. Riley, and D. Achor. 1992. Penetration through leaf stomata and growth of strains of Xanthomonas campestris in citrus cultivars varying in susceptibility to bacterial diseases. Phytopathology 82 : 1319-1325, doi: 10.1094/Phyto-82-1319.

Hiraoka, Y. 2020. Application of high-density SNP genotyping array in citrus germplasm characterization and genetic dissection of traits. University of California, Riverside, $\mathrm{PhD}$ Diss.

Irey, M., T.R. Gottwald, J.H. Graham, T.D. Riley, and G. Carlton. 2006. Post-hurricane analysis of citrus canker spread and progress towards the development of a predictive model to estimate disease spread due to catastrophic weather events. Plant Health Prog. August:1-12, doi: 10.1094/PHP-2006-0822-01-RS.

Kepiro, J.L. and M.L. Roose. 2009. AFLP markers closely linked to a major gene essential for nucellar embryony (apomixis) in Citrus maxima $\times$ Poncirus trifoliata. Tree Genet. Genomes 6:1-11.

Krueger, R.R. and M.L. Roose. 2003. Use of molecular markers in the management of citrus germplasm resources. J. Amer. Soc. Hort. Sci. 128:827-837, doi: 10.21273/JASHS.128.6.0827.

National Center for Biotechnology Information. 2020. Taxonomy browser, $X$. euvesicatoria pv. citrumelonis. 19 Apr. 2021. <https://www.ncbi.nlm.nih. gov/Taxonomy/Browser/wwwtax.cgi?lvl=0\&id=18 9396>.

Nicolosi, E., Z.N. Deng, A. Gentile, S. La Malfa, G. Continella, and E. Tribulato. 2000. Citrus phylogeny and genetic origin of important species as investigated by molecular markers. Theor. Appl. Genet. 100:1155-1166, doi: 10.1007/ s001220051419.

Omar, A.A., M. Murata, Q. Yu, F.G. Gmitter, Jr., C.D. Chase, J.H. Graham, and J.W. Grosser. 2017. Production of three new grapefruit cybrids with potential for improved citrus canker resistance. In Vitro Cell. Dev. Biol. Plant 53: 256-269, doi: 10.1007/s11627-017-9816-7.

Ramadugu, C., M.L. Keremane, S.E. Halbert, Y.-P. Duan, M.L. Roose, E. Stover, and R.F. Lee. 2016. Long-term field evaluation reveals HLB resistance in Citrus relatives. Plant Dis. 100: 1858-1869, doi: 10.1094/PDIS-03-16-0271-RE.

Richardson, M.L., C.J. Westbrook, D.G. Hall, E.W. Stover, Y.P. Duan, and R.F. Lee. 2011. Abundance of the citrus leafminer on Citrus and Citrus-related germplasm. HortScience 46:1260 1264, doi: 10.21273/HORTSCI.46.9.1260.

Stover, E., R. Driggers, M.L. Richardson, D.G. Hall, Y.P. Duan, and R.F. Lee. 2013. Incidence and severity of asiatic citrus canker on Citrus and Citrus-related germplasm in a Florida field planting. HortScience 49:4-9, doi: 10.21273/ HORTSCI.49.1.4.

Stover, E., G. McCollum, J. Ramos, and R.G. Shatters, Jr. 2015. Growth, health and Liberibacter asiaticus titer in diverse citrus scions on mandarin versus trifoliate hybrid rootstocks in a field planting with severe huanglongbing. Proc. Fla. State Hort. Sci. 127:53-59.

Vernière, C.J., T.R. Gottwald, and O. Pruvost. 2003. Disease development and symptom expression of Xanthomonas axonopodis pv. citri in various citrus plant tissues. Phytopathology 93: 832-843, doi: 10.1094/PHYTO.2003.93.7.832.

Westbrook, C.J., D.G. Hall, E.W. Stover, Y.P. Duan, and R.F. Lee. 2011. Colonization of Citrus and Citrus-related germplasm by Diaphorina citri (Hemiptera: Psyllidae). HortScience 46: 997-1005, doi: 10.21273/HORTSCI.46.7.997.

Xiang, C. and M.L. Roose. 1988. Frequency and characteristic of nucellar and zygotic seedlings in 12 citrus rootstocks. Scientia Hort. 37:4759, doi: 10.1016/0304-4238(88)90150-1. 